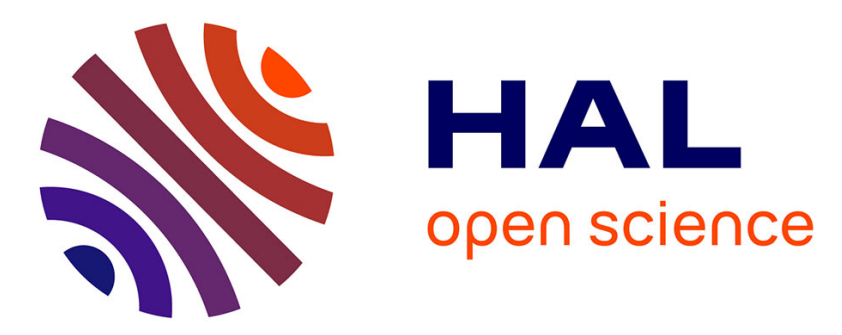

\title{
A simple steady-state model for the carry-over of aflatoxins from feed to cows milk
}

Jan van Eijkeren, Marco Zeilmaker, Martine Bakker

\section{To cite this version:}

Jan van Eijkeren, Marco Zeilmaker, Martine Bakker. A simple steady-state model for the carry-over of aflatoxins from feed to cows milk. Food Additives and Contaminants, 2006, 23 (08), pp.833-838. 10.1080/02652030600779890 . hal-00577302

\section{HAL Id: hal-00577302 \\ https://hal.science/hal-00577302}

Submitted on 17 Mar 2011

HAL is a multi-disciplinary open access archive for the deposit and dissemination of scientific research documents, whether they are published or not. The documents may come from teaching and research institutions in France or abroad, or from public or private research centers.
L'archive ouverte pluridisciplinaire HAL, est destinée au dépôt et à la diffusion de documents scientifiques de niveau recherche, publiés ou non, émanant des établissements d'enseignement et de recherche français ou étrangers, des laboratoires publics ou privés. 


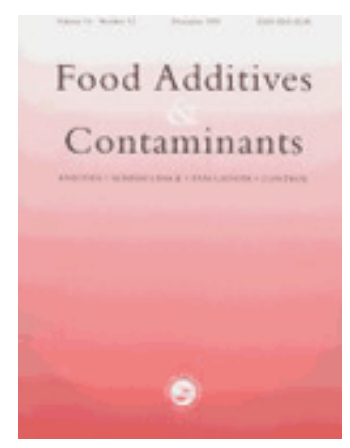

\section{A simple steady-state model for the carry-over of aflatoxins from feed to cows milk}

\begin{tabular}{|r|l|}
\hline Journal: & Food Additives and Contaminants \\
\hline Manuscript ID: & TFAC-2006-015.R1 \\
\hline Manuscript Type: & Original Research Paper \\
\hline $\begin{array}{r}\text { Date Submitted by the } \\
\text { Author: }\end{array}$ & 28-Apr-2006 \\
\hline Complete List of Authors: & $\begin{array}{l}\text { van Eijkeren, Jan; RIVM, SIR } \\
\text { Zeilmaker, Marco; RIVM, SIR } \\
\text { Bakker, Martine; RIVM, SIR }\end{array}$ \\
\hline Methods/Techniques: & Exposure modelling \\
\hline Additives/Contaminants: & Aflatoxins \\
\hline Food Types: & Animal feed \\
\hline
\end{tabular}

\section{SCHOLARONE Manuscripts}




\section{A simple steady-state model for the carry-over of aflatoxins}

2 from feed to cow's milk

3

4

5 Jan C.H. van Eijkeren", Martine I. Bakker and Marco J. Zeilmaker

6

7 National Institute for Public Health and the Environment; PO Box 1, Bilthoven, The

$8 \quad$ Netherlands

9

$10 *$ to whom correspondence should be addressed.e-mail:jan.van.eijkeren@ rivm.nl 


\section{Abstract}

12 A simple steady-state model is derived from two kinetic one-compartment models for

13 the disposition of aflatoxin $\mathrm{B}_{1}\left(\mathrm{AFB}_{1)}\right.$ and aflatoxin $\mathrm{M}_{1}\left(\mathrm{AFM}_{1}\right)$ in the lactating cow.

14 The model relates daily intake of $\mathrm{AFB}_{1}$ in feed of dairy cattle and the cow's lactation

15 status to resulting concentration levels of $\mathrm{AFM}_{1}$ in milk. Moreover, assuming a linear

16 relation between the cow's lactation status and feed intake, the model relates daily

17 milk production and $\mathrm{AFB}_{1}$ concentration in total feed to $\mathrm{AFM}_{1}$ levels in milk. The

18 model explains similar experimental outcomes from different experiments investigat-

19 ing carry-over of aflatoxins from feed to milk. Although it is concluded that it is diffi-

20 cult to set a limit for $\mathrm{AFB}_{1}$ in feed once and for all, in Europe the European Union

21 (EU) limit of $5 \mu \mathrm{g} \mathrm{AFB}_{1} / \mathrm{kg}$ of concentrate until now has proved to be appropriate to

22 prevent exceeding the EU-limit of $0.05 \mu \mathrm{g} \mathrm{AFM}_{1} / \mathrm{kg}$ milk.

23

24 Keywords: aflatoxin $\mathrm{B}_{1}$, aflatoxin $\mathrm{M}_{1}$, steady-state model, animal feed 


\section{7}

28

\section{Introduction}

Aflatoxins are known for their carcinogenic, mutagenic and teratogenic properties (Van Egmond, 1989). They have been found, amongst others, in groundnuts, cottonseed and corn, which are constituents in different formulations of concentrate rations fed to dairy cattle. Aflatoxin $B_{1}$ is the most abundant of the aflatoxins. They are secondary metabolites of some Aspergillus fungi. In mammals $\mathrm{AFB}_{1}$ is metabolised to $\mathrm{AFM}_{1}$, which is excreted in milk. Both $\mathrm{AFB}_{1}$ and $\mathrm{AFM}_{1}$ are very toxic and potent liver carcinogens. Several authors, e.g., references in Van Egmond (1989), Frobish et al. (1986), Veldman et al. (1992), Chopra et al. (1999), have investigated the relation between intake of aflatoxins in feed of dairy cattle and the resulting $\mathrm{AFM}_{1}$ levels in milk, depending on (equivalent) $\mathrm{AFB}_{1}$ level in (total) feed, daily intake of $\mathrm{AFB}_{1}$ and lactation status. However, no modelling effort, unifying the different investigations and explaining common observations, was made.

A model based on mechanistic considerations was developed. This includes the fractional absorption of daily ingested $\mathrm{AFB}_{1}$ over the gut wall, its metabolism to $\mathrm{AFM}_{1}$ and its elimination by other ways, the corresponding formation of $\mathrm{AFM}_{1}$ and the excretion of $\mathrm{AFM}_{1}$ through milk and its elimination by other ways. From the steadystate analysis of this model, the carry-over rate (COR) from $\mathrm{AFB}_{1}$ to $\mathrm{AFM}_{1}$, i.e. the ratio of the daily amount of $\mathrm{AFM}_{1}$ excreted by milk and the daily amount of $\mathrm{AFB}_{1}$ ingested was modelled. Additionally, the bioconcentration factor (BCF), i.e. the ratio of $\mathrm{AFM}_{1}$ concentration in milk and $\mathrm{AFB}_{1}$ concentration in feed, follows from the steady state analysis. When it is assumed that feed intake depends linearly on daily milk production, then the $\mathrm{BCF}$ could be expressed in terms of lactation status only. 
52

53

54 2

\section{Materials and Methods}

The number of animals per experimental group for the studies utilised in this paper is low. Frobish et al. (1986) used 4 animals per group, Veldman et al. (1992) used 12 and 8 animals per group and Chopra et al. (1999) used 10 animals in their repeated experiment. But also other authors generally seem to use a number of animals of the same order (van Egmond, 1989). A general remark is that the inter-individual variability regarding the resulting $\mathrm{AFM}_{1}$-level in milk is great. Moreover, different studies use different races, different composition of concentrate, different source of contamination (naturally contaminated corn, cottonseed or groundnuts) and different composition of additional feed.

(6)

63 The mechanistic model for carry-over of $\mathrm{AFB}_{1}$ to $\mathrm{AFM}_{1}$ is shown in Figure 1. A fraction, $F$ of the daily intake $\dot{D} \mu \mathrm{g} /$ day of $\mathrm{AFB}_{1}$ is taken up over the gut wall (in this paper dotted symbols denote quantities per time unit). This fraction may well depend on the matrix/carrier of $\mathrm{AFB}_{1}$ and thus can be different for different $\mathrm{AFB}_{1}$ contamination sources (groundnuts, cottonseed and corn), different concentrate composition and different total feed composition. The daily intake $\dot{D}$ of $\mathrm{AFB}_{1}$-equivalents is the product of the total daily feed intake $\dot{I}_{\text {feed }}(\mathrm{kg}$ feed / day) and the total feed concentration

0

$1 \quad C_{\text {feed }}\left(\mu \mathrm{g} \mathrm{AFB}_{1} / \mathrm{kg}\right.$ feed): $\dot{D}=\dot{I}_{\text {feed }} \cdot C_{\text {feed }}$.

3 In the one-compartment model, the amount $A_{B}$ taken up over the gut wall results in a plasma concentration $C_{B}=A_{B} / V_{B}$, where $V_{B}$ is the distribution volume of $\mathrm{AFB}_{1}$, i.e. the equivalent to the body tissues volume of the volume of pure plasma to reach that 
76

77

78

87

88

concentration. $\mathrm{AFB}_{1}$ is cleared from plasma by urinary excretion (after GSHconjugation) or by transformation to metabolites that are of no further toxicological interest (clearance $C L_{B}$ in $\mathrm{L} /$ day) and by transformation to the metabolite of interest $\mathrm{AFM}_{1}$ (clearance $C L_{B: M}$ in $\mathrm{L} /$ day). Once $\mathrm{AFM}_{1}$ has been formed in the liver, it results in a plasma concentration $C_{M}=A_{M} / V_{M}$, where $V_{M}$ is the distribution volume of $\mathrm{AFM}_{1}$. Also $\mathrm{AFM}_{1}$ is cleared from plasma by elimination through other means than milk ( $C L_{M}$ in L/day) and by excretion through milk: $P_{m} \dot{M}$ L/day, where $P_{m}$ is the milk:plasma partition of $\mathrm{AFM}_{1}$ and $\dot{M}$ is the milk production in $\mathrm{kg} / \mathrm{day}$.

A coupled set of mass balances describes the carry-over of $\mathrm{AFB}_{1}$ in feed to $\mathrm{AFM}_{1}$ in milk:

$$
\begin{aligned}
& \frac{d A_{B}}{d t}=F \dot{D}-\left(C L_{B}+C L_{B: M}\right) \cdot C_{B} \\
& \frac{d A_{M}}{d t}=C L_{B: M} \cdot C_{B}-\left(C L_{M}+P_{m} \dot{M}\right) \cdot C_{M}
\end{aligned}
$$

The first line in equation (1) shows the rate of change of the body burden of $\mathrm{AFB}_{1}$ $d A_{B} / d t$ after the fractional systemic uptake $F$ of the daily ingested amount $\dot{D}$ through contaminated feed and the concurrent clearance from plasma by elimination $\left(C L_{B}\right)$ and $\mathrm{AFM}_{1}$-formation $C L_{B: M}$. The second line shows the rate of change of the body burden of $\mathrm{AFM}_{1} d A_{M} / d t$ and its concurrent clearance from plasma by elimination $\left(C L_{M}\right)$ and excretion through milk, $P_{m} \dot{M}$. Note that the daily milk excretion is $P_{m} \dot{M} C_{M}$, which is the product of the daily milk production $\dot{M}(\mathrm{~kg} / \mathrm{day})$ and the concentration of $\mathrm{AFM}_{1}$ in milk $P_{m} C_{M}$. 
98 In this study we are interested in the case that contamination is sustained and steady

99 state will be reached. From equation (1), setting the rates of change to zero, one ob-

100 tains readily the steady state concentrations in plasma:

101

102

$$
C_{B}=\frac{F \dot{D}}{C L_{B}+C L_{B: M}}
$$

$$
C_{M}=\frac{C L_{B: M} \cdot C_{B}}{C L_{M}+P_{m} \dot{M}}=\frac{C L_{B: M}}{C L_{M}+P_{m} \dot{M}} \cdot \frac{F \dot{D}}{C L_{B}+C L_{B: M}}
$$

103

104 where in the second line the resulting steady state concentration of $\mathrm{AFB}_{1}$ is substituted 105 from the first line.

106

107 The corresponding $\mathrm{AFM}_{1}$-level in milk at steady state is:

108

$$
C_{m i l k}=P_{m} C_{M}=\frac{P_{m} C L_{B: M}}{C L_{M}+P_{m} \dot{M}} \cdot \frac{F \dot{D}}{C L_{B}+C L_{B: M}}
$$

111 Dividing through the milk:plasma partition coefficient $P_{m}$ end defining the constants

$$
\alpha=\frac{F \cdot C L_{B: M}}{C L_{B}+C L_{B: M}}, \quad \beta=\frac{C L_{M}}{P_{m}}
$$

114

115 the resulting steady state $\mathrm{AFM}_{1}$ concentration in milk can be expressed in terms of the

116 "free" variables of daily dose and lactation status:

117

118

$$
C_{m i l k}=\frac{\alpha \dot{D}}{\beta+\dot{M}}
$$


119

120

121 Two additional quantities can be derived from equation (5): the carry-over-rate 122 (COR), which is the relation between the daily $\mathrm{AFB}_{1}$ intake and the daily $\mathrm{AFM}_{1}$ ex123 cretion through milk and the bio-concentration factor (BCF), which is the ratio be124 tween the $\mathrm{AFM}_{1}$-level in milk and in $\mathrm{AFB}_{1}$-level in total feed:

125

128 Note that the COR is only dependent on lactation status and the BCF only on daily

129 feed intake and lactation status.

130

131 Additionally, when it is assumed that there exists a linear relationship between daily

132 milk production and feed intake:

133

136 ( $\dot{B}$ is intake for self maintenance when no milk is produced) then $C_{\text {milk }}$ in equation

137 (5) can be expressed in terms of lactation status and feed concentration, and so the 138 corresponding BCF of equation (6) is no longer dependent on feed intake and lacta139 tion status, but on the latter only:

140

$$
C_{\text {milk }}=\frac{\alpha \cdot(A \cdot \dot{M}+\dot{B})}{\beta+\dot{M}} \cdot C_{\text {feed }}, \quad B C F=\frac{\alpha \cdot(A \cdot \dot{M}+\dot{B})}{\beta+\dot{M}}
$$


143

144 Van Egmond (1989; chapter 2) shows a compilation of data from Sieber and Blanc

145 (1978) which clearly indicates that there is a linear relationship between $\mathrm{AFB}_{1}$ intake

146 and $\mathrm{AFM}_{1}$ levels in milk. This is consistent with model equation (5), be it that it may

147 be expected that the slope of the linear relationship differs from the different investi-

148 gations, which it does, mainly depending on the kind of contamination and lactation

149 status.

150

151 The model of equation (5) has been fit to data, concerning concentrate containing

152 naturally contaminated cottonseed, from Frobish et al. (1986), see Figure 2. The re-

153 sulting empirical parameter values found are $\alpha=0.032, \beta=17$. Of the six data

154 points, one appears to be an outlier: its low milk level would indicate cows at high

155 production, while in fact production is low. Frobish et al. also present $\mathrm{AFB}_{1}$ levels in

156 total feed and thus daily intake of feed can be estimated. The result of linear regres-

157 sion of daily intake versus production status is presented in Figure 3. The resulting

158 optimised parameter values are $A=0.43, \dot{B}=10$. Note that, because of their clustering

159 the data do not allow for a definite conclusion that a linear relation exists between in-

160 take and production level. However, for the range of milk production levels the model

161 may assumed to be adequate. If so, the model for milk levels and bio-concentration

162 factors of equation (8) apply.

163

164 In a second trial, concentrate containing contaminated cottonseed was used again, as

165 well as concentrate containing naturally contaminated corn. In Table 1 observed

$166 \mathrm{AFM}_{1}$-levels in milk are compared with levels estimated by applying the models in

167 equation (5) and (8). For cottonseed all the estimated levels exceed observed level, but 
168 within $20 \%$ at maximum. The estimations for carry-over from corn are about 1.5 -fold 169 greater than determined experimentally. As the animals got the same diet, but with the 170 corn portion contaminated instead of the cottonseed portion, this must be due to dif171 ference in the typical aflatoxin mix of naturally contaminated corn as compared to that 172 of cottonseed. This implies a difference in the factor $\alpha$ in equation (5).

173

174 Given the parameterisation in equation (5), the maximum carry-over-rate possible $175=\alpha=0.032(3.2 \%)$. Values of milk production in the study or cottonseed ranged 176 from a minimum of $14.6 \mathrm{~L}$ /day to a maximum of $32.9 \mathrm{~L} /$ day, and consequently the 177 model calculated COR (for cottonseed) should range from 0.015 (1.5\%) to 0.021 178 (2.1\%). Values of $1.38 \%$ to $2.33 \%$ are reported, except for $15.2 \mathrm{~kg}$ milk per day pro179 ducing lot (which is also exceptional in Figure 2). In concordance with our model, it is 180 remarked that $\mathrm{AFB}_{1}$-level in feed did not affect COR (equation (6)), but that COR was 181 positively correlated with increased milk production (equation (6)).

182

183 Also, it is reported that milk production did not affect $\mathrm{AFM}_{1}$-levels in milk. When 184 feed intake is linearly dependent on milk production and equation (8) applies, this 185 should imply that, at least within the range of milk production in the study, BCF is 186 (almost) independent of $\dot{M}$. In the range $\dot{M}=14.6-32.9$, BCF ranges between the 187 values 0.0155 and 0.0165 . So, an explanation of the independence of $\mathrm{AFM}_{1}$-levels on 188 milk production may lie in the validity of both the models in equation (5) (derived 189 from mechanistic considerations) and (7) (assuming linear relationship between daily 190 feed intake and milk production). Linear dependence of $\mathrm{AFM}_{1}$-level in milk on $\mathrm{AFB}_{1}$ 191 level in feed is implied both by equation (5) and (8). 
193 In a two experiment study of Veldman et al. (1992), concentrate with naturally con-

194 taminated groundnuts was used. Note that also in this case, quantitative model calcu-

195 lations using the parameters found above, notably the parameter $\alpha$, need not be simi-

196 lar to experimental observations. Qualitative model aspects however, should not dif-

197 fer. Nevertheless, application of model equation (5) to experimental results of experi-

198 ment 1 do not fit: while daily intake for high and low producing cows are similar (39

199 and $34 \mu \mathrm{g} / \mathrm{day}$, respectively), mean $\mathrm{AFM}_{1}$-level in milk of the high producing cows

200 exceeds 1.5-fold the corresponding mean level in low producing cows: one would ex-

201 pect the reverse, because of the more efficient excretion route through milk. This ex-

202 perimental result is also not consistent with the result of the second experiment, nor

203 with experimental results of other researches. The results of experiment 2 are consis-

204 tent with the model, indicating that the $\mathrm{BCF}$ of $\mathrm{AFB}_{1}$ to $\mathrm{AFM}_{1}$ from groundnuts to be 205 a factor of 1.6 greater than the BCF from cottonseed.

207 From the second experiment it is concluded by the authors that 1 . COR is positively 208 correlated with milk production (our equation (6)), 2. given a fixed $\mathrm{AFB}_{1}$ intake the 209 corresponding $\mathrm{AFM}_{1}$-level in milk is negatively correlated to milk production (our 210 equation (5)) and 3. COR is independent of $\mathrm{AFB}_{1}$-level in feed (our equation (6)).

212 Model calculations (equation (5)) with the parameterization as found above applied to 213 result from Chopra et al. (1999) can reasonably explain their findings. However, cal214 culated concentrations appear to be 2 -fold $( \pm 0.5)$ higher than the concentrations found 215 experimentally. The cows were fed concentrate with naturally contaminated ground216 nuts, as in the research of Veldman et al. This last research found concentrations that 217 appear to be about 1.6 higher than the calculated concentrations based on parameters 
218 found for Frobish et al. So, concentrations found by Veldman et al. exceed those

219 found by Chopra et al. by a factor of about 3.2. This may be partly due to matrix ef-

220 fects: apart from different concentrate compositions, cows in Chopra et al. were fed 221 green maize and wheat straw, cows in Veldman et al. grass and maize silage. More222 over, it is not clear whether the ration was contaminated naturally. Applebaum et al. 223 (1982) report an increased $\mathrm{AFM}_{1}$-level in milk when naturally contaminated portion 224 was administered compared to an equivalent contamination level with pure $\mathrm{AFB}_{1}$.

\section{Discussion}

227 Different investigators studied the carry-over of $\mathrm{AFB}_{1}$ (in fact $\mathrm{AFB}_{1}$-equivalents of a 228 natural mixture of aflatoxins) from feed to cows milk under different conditions such 229 as lactation status, source of contamination, contaminated concentrate composition 230 and total feed composition. From the pharmacological and toxicological literature, it 231 is well known that the carrier of the contamination [i.e., in the following order, source 232 of contamination (corn, cottonseed, groundnuts), concentrate composition and total 233 feed composition] generally influence its absorption over the gut wall. As the natural 234 contamination is expressed in terms of $\mathrm{AFB}_{1}$-equivalents and only $\mathrm{AFB}_{1}$ will be trans235 formed to $\mathrm{AFM}_{1}$, both feed composition and kind of source will lead to different 236 quantitative outcome of the different experiments. Indeed, different recommendations 237 with respect to daily intake per animal and of corresponding concentrate contamina238 tion level may be expected. e.g., Veldman et al. (1992) recommend a daily intake of $239 \mathrm{AFB}_{1}$ per cow below $40 \mu \mathrm{g}$, Munksgaard et al. (1987) below $60 \mu \mathrm{g}$ and Chopra et al. 240 (1999) below $70 \mu \mathrm{g}$. Corresponding recommended $\mathrm{AFB}_{1}$-levels in concentrate in 241 Munksgaard et al. (1987) and Veldman et al. (1992) are $10 \mu \mathrm{g} / \mathrm{kg}$ and $3-4 \mu \mathrm{g} / \mathrm{kg}$, 242 respectively. As daily concentrate intake in Chopra et al. is about $3 \mathrm{~kg} / \mathrm{day}$, one could 
243 derive a recommended concentrate contamination level of $23 \mu \mathrm{g} / \mathrm{kg}$. Scaling the result

244 in Frobish et al. to the current $\mathrm{AFM}_{1}$ EU-limit in milk of $0.05 \mu \mathrm{g} / \mathrm{kg}(0.5 \mu \mathrm{g} / \mathrm{kg}$ milk 245 in 1986), the recommended level would be $3.3 \mu / \mathrm{kg}$ concentrate. This assumes the 246 conversion in the liver of $\mathrm{AFB}_{1}$ to $\mathrm{AFM}_{1}$ to be non-saturated within a tenfold range 247 (see also Veldman et al. (1992))

249 Despite the expected different quantitative outcome, a qualitative outcome similar to 250 all experiments is reported. In order to unify these studies, a simple steady state model 251 has been developed [see equation (5)]. This model is based on the steady state analy252 sis of a mechanistic model describing the kinetics of carry-over of $\mathrm{AFB}_{1}$ in feed to $253 \mathrm{AFM}_{1}$ in milk [see figure 1 and equation (1)]. Though this model lacks an accurate 254 description of the initial phase of contamination, when $\mathrm{AFB}_{1}$-levels in plasma and, 255 consequently, $\mathrm{AFM}_{1}$-levels in milk probably change rapidly, it may offer a sufficient 256 description of the terminal phase of contamination, when levels change slowly and 257 reach steady-state.

259 The simple model, derived from the steady-state analysis contains two experimentally 260 observable parameters, the contamination rate and the milk production rate, and two 261 empirical constants. These constants will depend on the cows race, the source of con262 tamination (cottonseed, corn, groundnuts, etc.), and the composition of concentrate 263 fed together with the composition of total feed. E.g., races will most probably differ in 264 their metabolism (both pathways available and kinetics), which influences both pa265 rameters [see equation (4)]. Different sources of $\mathrm{AFB}_{1}$, will lead to different fractions 266 of the amount of the mixture of aflatoxins that, eventually, may be transformed to $267 \mathrm{AFM}_{1}$, thus influencing the parameter $\alpha$ in the model. In the same cow, regardless of 
268 the source, the parameter $\beta$ is a given constant. The contaminated material that is ap269 plied to the concentrate does not only determine the typical natural contaminating 270 aflatoxin composition, but also serves as a different matrix/carrier. This aspect is fur271 ther influenced by concentrate composition and, indeed, by the total feed composition.

273 Nevertheless, from the model one can derive the observed aspects of carry-over from $274 \mathrm{AFB}_{1}$ in feed to $\mathrm{AFM}_{1}$ in milk. Milk levels $C_{\text {milk }}$ of $\mathrm{AFM}_{1}$ are independent of feed 275 levels $C_{\text {feed }}$ of $\mathrm{AFB}_{1}$ when the rate of contamination in $\dot{D}=\dot{I}_{\text {feed }} \cdot C_{\text {feed }}$ is a constant 276 [equation (5)]. Carry-over rate is higher in high milk producing cows than in low pro277 ducing ones [equation (6)]. Correspondingly, $\mathrm{AFM}_{1}$-levels in milk are higher in low 278 producing cows than in high producing ones at the same rate $\dot{D}$ of $\mathrm{AFB}_{1}$ contamina279 tion [equation (5)]. Carry-over rate is independent of the rate of contamination [equa280 tion (6)].

282 Furthermore, it was assumed that, at least in the range between low and high milk 283 production, total feed intake was linearly related to milk production level [equation 284 (7)]. Under this assumption, also BCF is independent of the contamination rate and 285 depends on milk production only [equation (8)]. The parameters found for one study 286 (Frobish et al.) indicate that BCF varies only slightly in the range between low and 287 high milk production, corroborating the observation that BCF is independent of milk 288 production.

290 Given a limit $\mathrm{AFM}_{1}$-level in milk, equation (5) may help in deriving the correspond291 ing limit for $\mathrm{AFB}_{1}$ - intake, or, indirect, for $\mathrm{AFB}_{1}$-level in total feed. Likewise, equa292 tion (8) directly relates $\mathrm{AFM}_{1}$-levels in milk to $\mathrm{AFB}_{1}$-levels in total feed. Note that the 
293 limit for $\mathrm{AFB}_{1}$-intake depends on the milk production level. When feed intake rate is 294 linearly related to milk production, then under the condition that BCF is only slightly 295 dependent on milk production, the limit for $\mathrm{AFB}_{1}$-level in feed is independent of milk 296 production.

297

298 In conclusion, it seems that limits for $\mathrm{AFB}_{1}$ contamination (rate or concentration 299 level) related to a given limit for $\mathrm{AFM}_{1}$-level in milk depend on the cows race, the 300 source of contamination and total feed composition. Different authors conclude to dif301 ferent recommendations. Veldman et al. (1992) compare their recommendation of 302 concentrate contamination level not to exceed $3-4 \mu \mathrm{g} / \mathrm{kg}$ with the (still) current EU-

303 limit of $5 \mu \mathrm{g}$, and conclude that the latter does not guarantee the enforcement of the

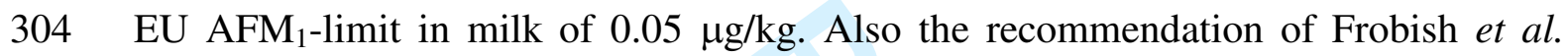
305 (1986) of $33 \mu \mathrm{g} \mathrm{AFB}_{1} / \mathrm{kg}$ concentrate, based on the former limit in milk of $0.5 \mu \mathrm{g}$ $306 \mathrm{AFM}_{1} / \mathrm{kg}$ milk when scaled to the current limit in milk, i.e. $3.3 \mu \mathrm{g} \mathrm{AFB}_{1} / \mathrm{kg}$ concen307 trate (well within the range of $3-4 \mu \mathrm{g} / \mathrm{kg}$ ) is below this limit. Nevertheless, in daily 308 practice, it seems that the EU-limit for $\mathrm{AFB}_{1}$ in concentrate $\left(5 \mu \mathrm{g} \mathrm{AFB}_{1} / \mathrm{kg}\right)$ prevents $309 \mathrm{AFM}_{1}$-levels to exceed the EU-limit of $0.05 \mu \mathrm{g} \mathrm{AFM}_{1} / \mathrm{kg}$.

\section{Acknowledgements}

312 This study was sponsored by Dr. A. Lam of the Food and Consumer Product Safety 313 Authority (VWA) of the Netherlands.

\section{References}


316 Applebaum, R.S., Brackett, R.E., Wiseman, D.W. and E.H. Marth. (1982), Responses

317 of dairy cows to dietary aflatoxin: feed intake and yield, toxic content and quality of

318 milk cows treated with pure and impure aflatoxin; J. Dairy Sci. 65:1503-1508

320 Chopra, R.C., Chhabra, A., Prasad, K.S.N., Dudhe, A., Murthy, T.N. and T. Prasad. 321 (1999) Carry-over of aflatoxin $\mathrm{M}_{1}$ in milk of cows fed aflatoxin $\mathrm{B}_{1}$ contaminated ra322 tion; Indian J. Anim. Nutr., 16:103-106

324 Frobish, R.A., Bradley, B.D., Wagner, D.D., Long-Bradley, P.E. and H. Hairston. 325 (1986). Aflatoxin residues in milk of dairy cows after ingestion of naturally contami326 nated grain; J. Food Protection, 49:781-785

328 Van Egmond, H.P. ed.; (1989) Mycotoxins in dairy products; Elsevier Science Pub329 lishers LTD, Essex, UK,.

331 Munksgaard, L., Larsen, J., Werner, H. and B.T. Viuf. (1987) Carry over of aflatoxin 332 from cows' feed to milk and milk products; Milchwissenschaft, 42: 165-167 333

334 Veldman, A., Meijst, J.A.C., Borggreve, G.J. and J.J. Heeres-van der Tol; Carry-over 335 of aflatoxin from cows' food to milk. (1992) Anim. Prod., 55, 163-168 
336 Table 1. Milk levels of $\mathrm{AFM}_{1}$ observed, estimated with the model in equation (5)

$337(\alpha=0.032, \beta=17)$ and the model in equation (8).

\begin{tabular}{|c|c|c|c|c|}
\hline $\begin{array}{l}\text { Production } \\
\text { level kg/day }\end{array}$ & $\begin{array}{l}\text { Daily AFB } 1 \\
\text { intake } \mu g\end{array}$ & \multicolumn{3}{|l|}{$\begin{array}{l}\mathrm{AFM}_{1} \text { milk } \\
\text { level } \mu \mathrm{g} / \mathrm{L}\end{array}$} \\
\hline \multicolumn{2}{|c|}{$44 \mu \mathrm{g}$ cottonseed $/ \mathrm{kg}$ total feed } & observed & model (5) & model (8) \\
\hline $30.4\left(n^{a}=4\right)$ & 966 & 0.62 & 0.65 & 0.69 \\
\hline $18.5(n=3)$ & 742 & 0.59 & 0.67 & 0.71 \\
\hline \multicolumn{2}{|c|}{$49 \mu \mathrm{g}$ corn $/ \mathrm{kg}$ total feed } & observed & model (5) & model (8) \\
\hline $31.2(n=4)$ & 1116 & 0.51 & 0.74 & 0.76 \\
\hline $20.0(n=4)$ & 885 & 0.55 & 0.77 & 0.79 \\
\hline
\end{tabular}

a: $\mathrm{n}$ is number of animals 
339 340

341 Figure 1. Kinetic model of the carry-over of $\mathrm{AFB}_{1}$ to $\mathrm{AFM}_{1}$. A fraction $\mathrm{F}$ of the daily 342 dose $\dot{D}$ enters the system over the gut wall. $\mathrm{AFB}_{1}$ is cleared by excretion and by bio343

356 Figure 3. Fit of intake versus milk production model of equation (7) to the data of 357 Frobish et al. (1986), table 3. The symbols denote experimentally determined values 358 and the straight line ( $A=0.43, \dot{B}=10$ ) shows the model fit. Note the clustering of 359

\section{Legends} transformation to toxicologically non-interesting metabolites (clearance $C L_{B}$ ) and to $\mathrm{AFM}_{1}$ (clearance $C L_{B: M}$ ). $\mathrm{AFM}_{1}$ is cleared by biotransformation to non-interesting metabolites or by excretion through toxicologically non-interesting ways (clearance $\left.C L_{M}\right)$ or by excretion through milk $\left(P_{m} \dot{M}\right)$, that has a milk:plasma partition coefficient $P_{m}$ and a daily production of $\dot{M}$. Plasma concentrations of $\operatorname{AFB}_{1}\left(C_{B}\right)$ and $\operatorname{AFM}_{1}\left(C_{M}\right)$ are the amounts of $\mathrm{AFB}_{1}$ and $\mathrm{AFM}_{1}$ divided by their distribution volume $\left(V_{B}\right.$ and $V_{M}$, respectively)

Figure 2. Fit of model equation (5) to the data from Frobish et al. (1986), table 3. Upper lines (experimental points: o) show the model for the three different low milk production levels and lower lines (experimental points: *) the model for the three different high milk production levels. Fitted parameter values: $\alpha=0.032, \beta=17$. data at the low and high production levels. 
360

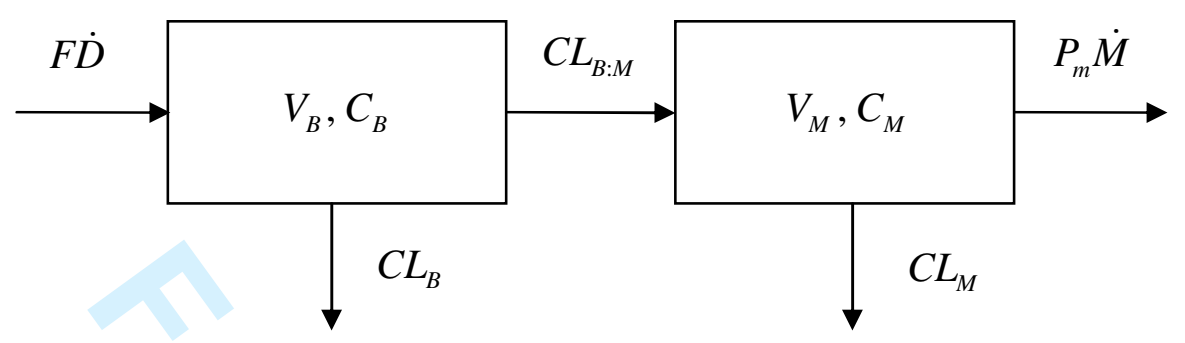

361

362 Figure 1.

http://mc.manuscriptcentral.com/tfac Email: fac@tandf.co.uk 


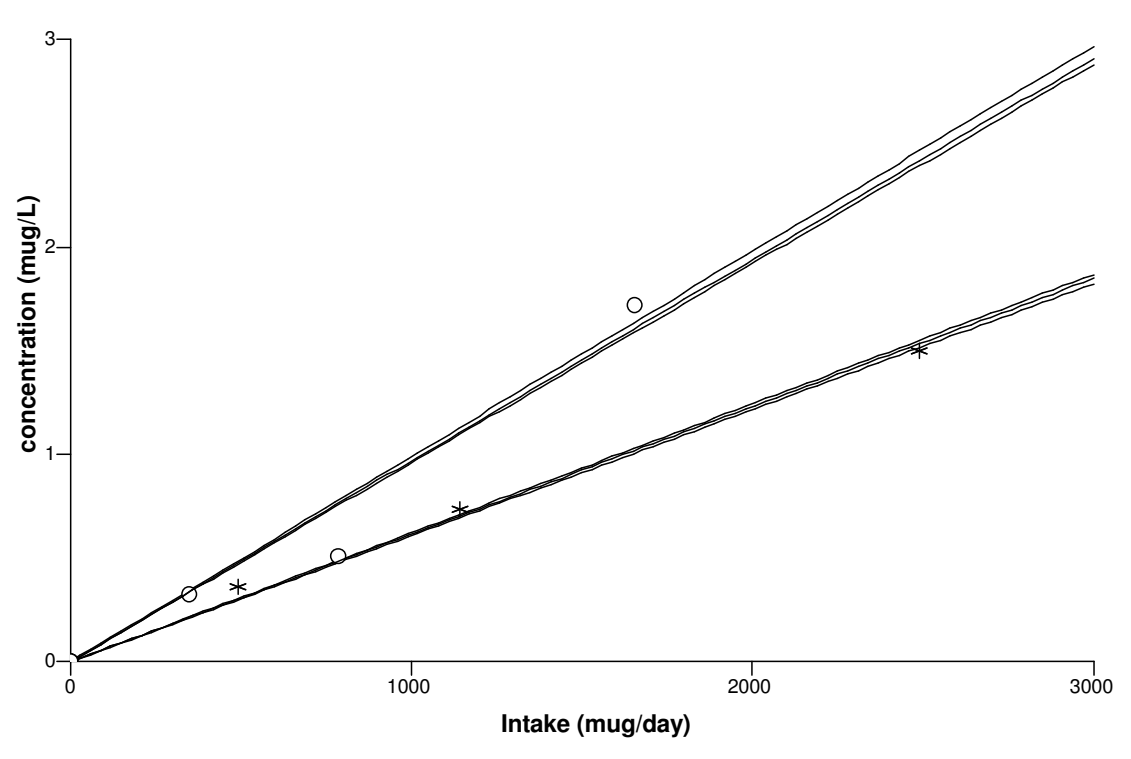

365 Figure 2. 
366

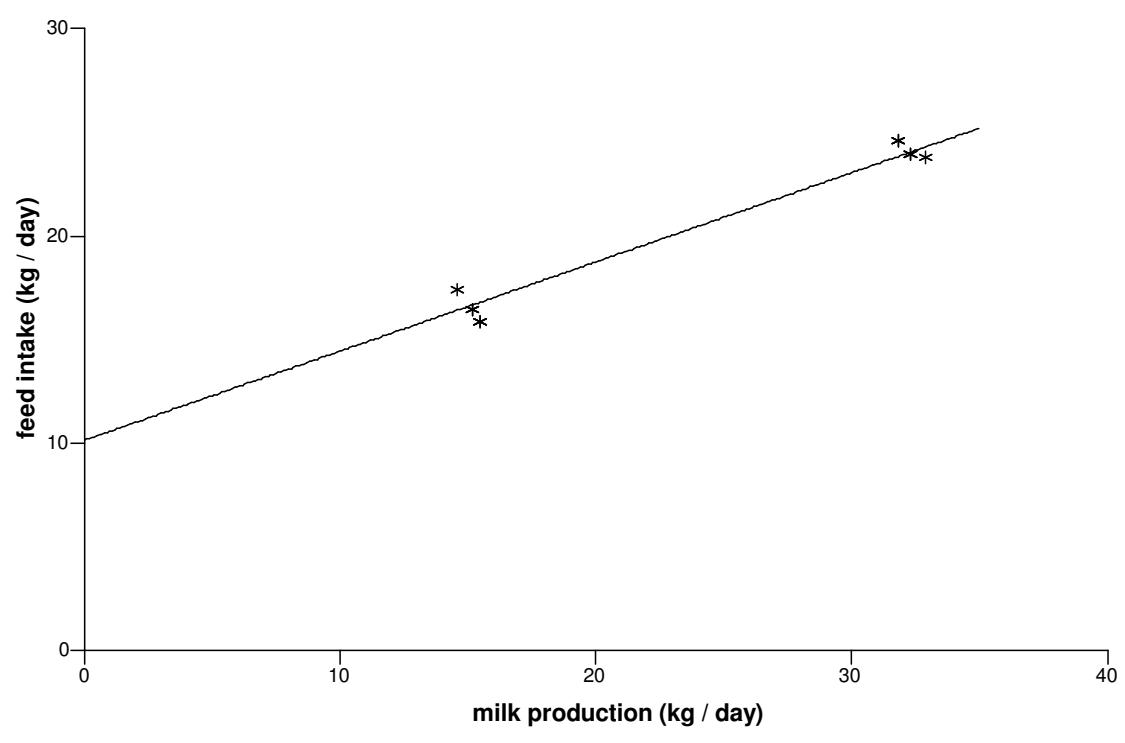

368 Figure 3.

http://mc.manuscriptcentral.com/tfac Email: fac@tandf.co.uk 